\title{
Erratum to: Impact of market access and comparative advantage on regional distribution of manufacturing sector
}

Muhammad Imran ${ }^{1 *}$, Gu Zhang ${ }^{2}$ and HuSen $A n^{1}$

* Correspondence: imranecon@hotmail.com

${ }^{1}$ Institute of Economic Research, School of Economics, Nankai University, Tianjin, China

Full list of author information is available at the end of the article

\section{Erratum}

After publication of the original article [1], it was noticed that "Equation 3.1" was incorrectly written. The correct "Equation 3.1" should be:

$$
B=\frac{{ }^{s} E \phi_{D}}{\Delta}+\frac{\left(1-s_{E}\right) \phi I}{\Delta^{*}}
$$

We sincerely apologize for the inconvenience caused.

\section{Author details}

'Institute of Economic Research, School of Economics, Nankai University, Tianjin, China. ${ }^{2}$ Lanzhou University, Gansu, China.

Received: 16 March 2017 Accepted: 16 March 2017

Published online: 27 March 2017

\section{Reference}

1. Imran M et al (2017) Impact of market access and comparative advantage on regional distribution of manufacturing sector. China Finance Econ Rev 5:4. doi:10.1186/s40589-017-0047-1 